\title{
ZONEAMENTO AGROCLIMÁTICO: LINHAS DE PESQUISA E CARACTERIZAÇÃO TEÓRICA-CONCEITUAL
}

\author{
Agro-climatic zoning: Research lines and characterization \\ theoretical and conceptual
}

Cássio Arthur Wollmann

Prof. Adjunto, Depto. de Geociências, Universidade Federal de Santa Maria cassio_geo@yahoo.com.br

Emerson Galvani

Prof. Dr., Depto. de Geografia, Universidade de São Paulo. Bolsista CNPq egalvani@usp.br

Artigo recebido em 25/06/2012 e aceito para publicação em 25/09/2012

RESUMO: Ao escolher, ou identificar-se, com determinada ciência, o pesquisador depara-se com infinidade de linhas de pesquisa, cada qual com suas metodologias, técnicas e referenciais teóricos recíprocos que the dão o aporte teórico-conceitual necessário ao desenvolvimento pleno da pesquisa, e consequentemente, da ciência para qual se dedica. Nesse sentido, procurou-se realizar um resgate teórico-metodológico acerca dos conceitos, linhas e pesquisas e aplicabilidades que envolvem as técnicas de zoneamento agroclimático. Inicialmente, dentro da Bioclimatologia Vegetal depara-se com diversas nomenclaturas de linhas de pesquisa, tais como Meteorologia Agrícola, Climatologia Agrícola, Agrometeorologia e Agroclimatologia. Independentemente do objeto de estudo abordado pelas linhas de pesquisa da Bioclimatologia Vegetal, há uma metodologia que é de grande uso pelos pesquisadores: o Zoneamento Agroclimático, que pode ser classificado como a delimitação da aptidão das regiões de cultivo quanto ao fator clima em escalas macroclimáticas e regionais. O Zoneamento Agrícola leva em consideração, além dos atributos climáticos, a associação de fatores como o solo (zoneamento edáfico), e o meio socioeconômico, com intuito de organizar a distribuição racional das culturas economicamente rentáveis, respeitando as características sociais e culturais de cada região, servindo, portanto, de base para o planejamento territorial do uso do solo. O Zoneamento Edafoclimático, é considerado um estudo de complementação da potencialidade natural de determinada região para dada cultura, no qual, além do clima, inserem-se no estudo os aspectos edáficos, ou pedológicos, e considerados, em geral, na mesma escala de análise do zoneamento agroclimático. Por fim, o zoneamento agrícola de risco climático, além das variáveis analisadas (clima, solo e planta), aplica-se funções matemáticas e estatísticas (frequencistas e probabilísticas) com o objetivo de quantificar o risco de perda das lavouras com base no histórico de ocorrência de eventos climáticos adversos, principalmente a seca e eventos de ocorrência de geadas em especial em latitudes médias.

PALAVRAS-CHAVE: Linhas de Pesquisa, Conceitos; Aplicações; Agroclimatologia.

ABSTRACT: When a researcher choose or identify himself with a science, he is faced with countless lines of research, each one with its own methodologies, techniques and theoretical development. Because of this reason, this article concerns in discuss concepts and lines of research involved in the agroclimatic zoning. In principle, inside of Bioclimatology which plants are the main focus, there are several classifications of research areas such as Agricultural Meteorology, Agricultural Climatology, Agrometeorology and Agroclimatology. Whatever will be the subject matter addressed by the research lines of Bioclimatology of plants, there is a technique / methodology that is largely used by researchers: the Agroclimatic Zoning, 


\begin{abstract}
whose concept is the delimitation and suitability of development and growing of plants in associations with regions where climate factor in macroclimatic and regional scales are the main question who need to be solved. The Agricultural Zoning takes care about the climatic attributes, the combination of factors such as soil (edaphic zoning), and socioeconomic environment, aiming to organize the rational distribution of crops economically viable, respecting the social and cultural characteristics of each region, serving, therefore, the basis for the territorial planning of land use. The Edaphic and Climatic Zoning has been considered as a complement to the natural potential of a region to plant a culture, in which, besides the climate, pedological aspects are in the study, and they have been studied in the same scale of Agroclimatic Zoning. To conclude, the Agricultural Zoning for Climatic Risks, beyond the variables (climate, soil and plant), applies mathematical and statistical functions (probabilistic in general) in order to quantify the risk of loss of plant culture based on historical occurrence of adverse weather events, especially drought and frost events occur especially in middle latitudes.
\end{abstract}

KEYWORDS: Research Lines, Concepts; Applications; Agroclimatology.

\section{INTRODUÇÃO}

A utilização das técnicas de Zoneamento Agroclimático podem ser consideradas frutos da investigação sobre as possíveis consequências da dinâmica e atuação de sistemas naturais sobre uma superfície que esteja sob domínio de um sistema de produção vegetal criado pelo homem. Essa dinâmica não se restringe apenas ao aumento à fertilidade e movimentos da água no solo, mas também aos movimentos atmosféricos, aos processos geomorfológicos e, principalmente, às repercussões socioeconômicas ocorridas nas áreas cultivadas, em especial nas áreas rurais.

Nesse sentido, ao se propor uma revisão teórico-metodológica sobre Zoneamento Agroclimático, procurou-se uma abordagem interdisciplinar, pois possuem alcance em praticamente a maioria das linhas de pesquisa das Ciências da Terra e Exatas, principalmente naquelas ligadas aos objetivos propostos para esta pesquisa, tais como a Climatologia, Meteorologia, Agronomia e Economia.

Buscou-se, inicialmente, discutir as linhas de pesquisa envolvidas em tais estudos, como a Meteorologia Agrícola, Climatologia Agrícola, Agrometeorologia e Agroclimatologia. Posteriormente, fundamentou-se o conceito de zoneamento agroclimático, pois se compara, muitas vezes, esta terminologia à sinônimos Zoneamento Agrícola, Edafoclimático e Ecológico.

\section{OBJETIVOS}

O objetivo deste artigo consistiu em propor um resgate teórico acerca das linhas de pesquisa, conceitos, aplicações e metodologias utilizadas nos estudos de Zoneamento Agroclimático, uma vez que tais pesquisas encontram-se publicadas em várias bibliografias, tendo-se como objetivo específico deste trabalho, a sistematização dos principais estudos e pesquisadores existentes nesta seara científica brasileira.

\section{FUNDAMENTAÇÃO TEÓRICA - DO CONCEI- TO, LINHAS DE PESQUISA E APLICABILI- DADE DO ZONEAMENTO AGROCLIMÁTICO}

Ao escolher, ou identificar-se, com determinada área da ciência, o pesquisador depara-se com diferentes linhas de pesquisa, cada qual com suas metodologias, técnicas, filosofias norteadoras e referenciais teóricos recíprocos que lhe dão o aporte teórico-conceitual necessário ao desenvolvimento pleno da pesquisa, e consequentemente, da ciência para qual se dedica.

Esse leque de pesquisas contidos em cada área da ciência também pode ser aplicado à Climatologia e à Meteorologia. Ao se trabalhar com a relação climática e/ou meteorológica para com as plantas e culturas agrícolas, por exemplo, podemos inserir tais linhas de pesquisa no campo da Bioclimatologia, na qual, Galvani (2004, p. 221), salienta que: 
A Bioclimatologia, de forma simplista, aplica os conhecimentos do Clima (Climatologia) às relações com os seres vivos. Salienta-se que a Bioclimatologia pode-se distinguir como Bioclimatologia Humana, Animal e Vegetal, quando enfoca, respectivamente, os seres humanos, os animais e os vegetais. Percebe-se que a Bioclimatologia, portanto, envolve uma gama de profissionais das mais diversas áreas a citar, sem estabelecer ordem de importância: Geografia, Agronomia, Meteorologia, Zootecnia, Engenharia Civil, Arquitetura, Biologia e outras ciências que de forma direta ou indireta se utilizam dos produtos da Bioclimatologia no equacionamento de seus problemas especificos.

A Bioclimatologia Vegetal, linha de pesquisa que se preocupa com a relação clima e plantas é colocada por Grisollet (1952) como uma linha que procura entender as razões pelas quais determinadas espécies não vivem fora de limites de valores apresentados pelos diferentes atributos climáticos, ocorrendo, assim, uma distribuição geográfica e climática das plantas.

Ainda, na Bioclimatologia Vegetal depara-se com diversas nomenclaturas de linhas de pesquisa, tais como Meteorologia Agrícola, Climatologia Agrícola, Agrometeorologia e Agroclimatologia. Segundo Smith (1975), a Meteorologia Agrícola tem como finalidade colocar a ciência meteorológica a serviço da agricultura, a fim de proporcionar um aumento na produção agrícola, evitando-se o abuso dos recursos naturais. Outros autores vão além à discussão do conceito. Para Mota (1985, p. 48-49), por exemplo:

A Meteorologia Agrícola pode ser definida como o estudo dos processos físicos na atmosfera, que produzem o tempo em suas relações com a produção agrícola. É uma ciência horizontal, a qual aplica a física do ar e do solo à agricultura... [ainda] o assunto de estudo na meteorologia agrícola é relacionado, principalmente, com as relações quantitativas como o meio atmosférico e as respostas biológicas das espécies vegetais cultivadas.
Em contrapartida, Robredo (1952) já definira que a Meteorologia Agrícola também poderia ser chamada de "Física Agrícola", cujo objeto de estudo está na ação da atmosfera sobre os vegetais, salientando que devem ser consideradas as condições médias da relação climática e a vida dos vegetais, observando-se, principalmente, a luz e a umidade. Nesse sentido, tanto Mota (op. cit.) quanto Robredo (op. cit.) salientam que o objeto de estudo da Meteorologia Agrícola é a relação clima e os vegetais, cujo estudo está baseado nos processos físicos da atmosfera e dos organismos biológicos, respectivamente, e com resultados eminentemente quantitativos.

Diferentemente da Meteorologia Agrícola, a Climatologia Agrícola avança seus estudos sobre demais áreas do conhecimento. Para Grisollet. et. al. (op. cit., p. 323), a Climatologia Agrícola contempla seis escalas de análise:

- A análise do clima como fator pedogenético;

- O clima e as diferentes fases de produção da cultura agrícola, tais como a necessidade de irrigação e poda;

- A influência dos elementos climáticos no desenvolvimento fenológico da cultura;

- Os aspectos climatológicos e os mecanismos de defesa das plantas em relação às "calamidades atmosféricas", como a geada, as imposições climáticas às atividades pós-colheita da cultura, como tipo de armazenamento/conservação/ climatização e transporte;

- Relação clima/altitude/relevo (relevo aqui entendido como as vertentes e sua exposição ao Sol) e suas influências ao desenvolvimento da cultura.

Ainda, o autor coloca que o climatologista, profissional capacitado para realizar este tipo de trabalho, deve realizá-lo em duas etapas distintas: Preparação e pesquisa de todo o material bibliográfico e cartográfico necessário (em escala e resolução compatíveis aos objetivos do estudo) que esteja relacionado aos conteúdos climáticos e geográficos; e o estudo da caracterização biológica da cultura a ser 
estudada e as influências sazonais do clima sobre o desenvolvimento da mesma.

A partir dessa etapa, o pesquisador chega às conclusões ligadas às relações climáticas e vegetais que inicialmente fizera como os elementos que mais influenciam na cultura, tanto quantitativo, épocas de plantio e colheita e apresenta soluções para o planejamento do calendário agrícola.

A Agrometeorologia, outra linha de pesquisa que estuda a influência do clima sobre os vegetais, é colocada por Mota (op. cit., p. 48) como sendo uma linha interdisciplinar, ampla e complexa. Segundo ele, “... os pesquisadores deste campo devem ter uma compreensão íntima dos problemas agrícolas e meteorológicos, pois envolvem considerações de Biologia, Física, Meteorologia e Economia".
Ainda, Mota (op. cit.) salienta que é necessário o conhecimento da influência exercida pelo clima sobre os organismos vivos, especialmente a influência dos "azares climáticos", colocando que se torna indispensável, tanto o uso quanto o desenvolvimento de tecnologias adequadas que possuem a finalidade de produzir maiores rendimentos, tanto culturais quanto econômicos, independentemente da existência de condições climáticas desfavoráveis ao desenvolvimento pleno de determinada cultura. Para melhor ilustrar as relações interdisciplinares da Agrometeorologia, a Figura 01 traz um esquema apresentado por Mota (op. cit.).

Figura 01 - A Agrometeorologia e as Ciências correlatas

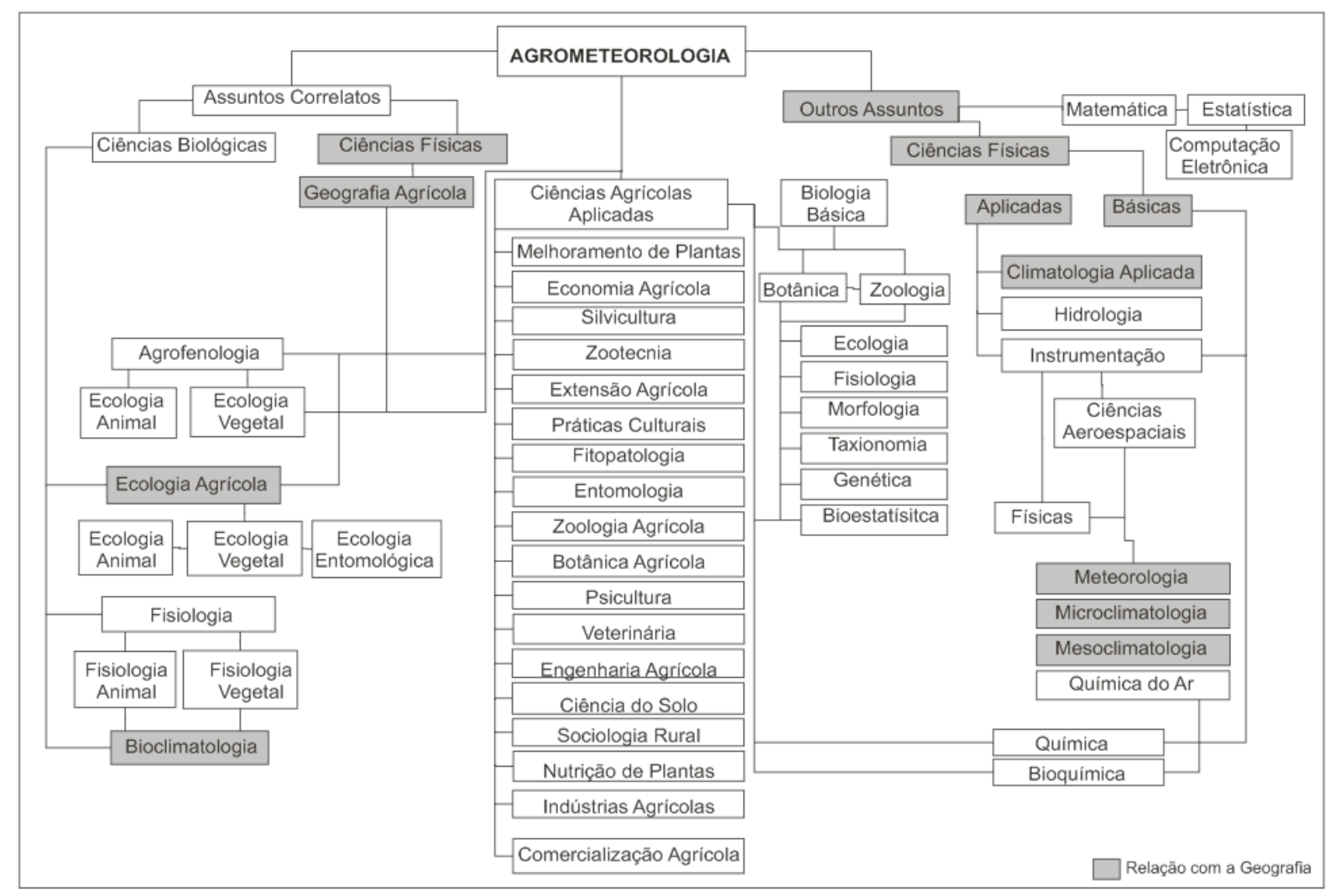

Fonte: Mota, F. (op. cit., p. 56), adaptado. 
Conforme Pereira; Angelocci; Sentelhas (2002), o objetivo da Agrometeorologia é a maximização da exploração econômica dos recursos naturais, obviamente, com a conscientização da preservação ambiental, entretanto tal maximização depende da introdução de tecnologias produtivas, pois, segundo os autores:

As condições atmosféricas afetam todas as etapas das atividades agricolas (...). As conseqüências de situações meteorológicas adversas levam constantemente a graves impactos sociais, e a enormes prejuizos econômicos, muitas vezes dificeis de serem quantificados... como as condições adversas do tempo são freqüentes, muitas vezes imprevisiveis a médio e longo prazo, a agricultura constitui-se e, atividade de grande risco (PEREIRA; ANGELOCCI; SENTELHAS, 2002, p. 24).

Por fim, a Agroclimatologia possui como objeto de estudo o conhecimento do clima e do tempo com o objetivo de se intensificar a produção agrícola do solo, seja seu uso voltado às atividades agropecuárias ou florestais. Conforme Burgos (1967, p. 87):

O processo do tempo e de clima, por sua parte, é um complicado mecanismo composto por muitos elementos que inter-relacionam e pulsam com relativa regularidade. A distribuição temporal de tais elementos e os desvios que mostram com respeito essa regularidade condiciona, direta ou indiretamente, as variações que experimentam, ano após ano, a produção do solo. As combinações destes elementos e sua distribuição espacial sobre a superficie terrestre determinam o tempo de exploração possivel do solo e os índices geográficos de sua produtividade [tradução nossa].

Além disso, o autor ressalta que é necessário investigar quais elementos do clima e quais valores são os responsáveis pelos melhores rendimentos da cultura em análise, baseando-se, inicialmente, em testes estatísticos, que sempre estão associados a estas buscas por melhores rendimentos nas culturas, bem como em uma infraestrutura física e profissional, como os centros de investigação agrometeorológica e agroclimática, que possam lhe oferecer as informações fidedignas e necessárias.

O autor ainda ressalta que, cabe ao agroclimatologista conhecer a evolução do tempo e o calendário de exploração agrícola da cultura. Ressalta, pioneiramente, a importância dos estudos de circulação geral da atmosfera, que deve ser realizada com a coleta de dados de estações meteorológicas de superfície e mapas de pressão atmosférica, salientando a importância de se estudarem os sistemas frontais nos meses de janeiro e julho para a América do Sul, como os principais produtores do tempo e do clima.

Independentemente do objeto de estudo abordado pelas linhas de pesquisa da Bioclimatologia Vegetal, uma metodologia, ou tecnologia, como é vista para alguns autores, é de grande e comum uso pelos pesquisadores: o Zoneamento Agroclimático. Para Ometto (1981, p. 405), esse zoneamento é “... a escolha dos locais mais indicados para as diversas culturas, a fim de obter-se uma maior rentabilidade do capital investido", bem como para a conservação dos recursos naturais (KIMBALL; GILBERT, 1970).

Entretanto, o zoneamento com finalidade de uso para as atividades agrícolas possui algumas classificações quanto ao objetivo proposto e resultados alcançados. Unindo as considerações feitas por Ometto (op. cit), Pereira; Angelocci; Sentelhas (op. cit.), e o Ministério da Agricultura, Pecuária e Abastecimento (MAPA, 2010), o zoneamento voltado para as atividades agrícolas podem ser divididos em quatro categorias: Zoneamento Agroclimático; Zoneamento Agrícola; Zoneamento Agroecológico ou Edafoclimático; e Zoneamento de Riscos Climáticos;

O Zoneamento Agroclimático preocupa-se com o macroclima, e de acordo com Pereira; Angelocci; Sentelhas (op. cit., p. 435).

O macroclima não pode ser mudado para se adequar às necessidade do cultivo. No entanto, dentro do clima regional o agricultor pode escolher as nuances do relevo (topoclima) que melhor acomoda uma dada cultura. Isto envolve planejamento a nivel de propriedade agrícola e deve ser feito localmente, por 
especialista daquela cultura. O zoneamento macroclimático não entra em detalhes topoclimáticos, pois esta é uma função do agrônomo regional e do produtor rural, e depende da análise das condições de cada fazenda.

Em resumo, o Zoneamento Agroclimático é a delimitação da aptidão das regiões de cultivo quanto ao fator clima em escalas macroclimáticas e regionais. Entretanto, Mota; Agendes (1986) ressaltam que os zoneamentos macroclimáticos podem ser muito gerais e pouco confiáveis, sendo mais detalhados e recomendados os zoneamentos agroclimáticos em escalas associadas ao estudo da Climatologia Regional.

O Zoneamento Agrícola, por sua vez, leva em consideração, além dos elementos do clima, a associação de fatores ou critérios como o solo (zoneamento edáfico), e o meio socioeconômico, com o intuito de organizar a distribuição racional das culturas economicamente rentáveis, respeitando as características sociais e culturais de cada região (OMETTO, op. cit.), servindo, portanto, de base para o planejamento territorial do uso da terra (PEREIRA; ANGELOCCI; SENTELHAS, op. cit).

O Zoneamento Edafoclimático, é considerado um estudo de complementação da potencialidade natural de determinada região para dada cultura, no qual, além do clima, inserem-se no estudo os aspectos edáficos, ou pedológicos (OMETTO, op. cit.), e considerados, em geral, na mesma escala de análise do zoneamento agroclimático.

Por fim, o Zoneamento de Riscos Climáticos, conforme o Ministério da Agricultura, Pecuária e Abastecimento - MAPA (2010):

"diferentemente de outros zoneamentos existentes, que foram elaborados com base nos conceitos de potencialidade e aptidão, para o zoneamento agrícola de risco climático, além das variáveis analisadas (clima, solo e planta), aplicam-se funções matemáticas e estatísticas (frequencistas e probabilisticas) com o objetivo de quantificar o risco de perda das lavouras com base no histórico de ocorrência de eventos climáticos adversos, principalmente a seca. Com isso, após anali- sar séries históricas de dados meteorológicos identifica-se para cada municipio e a melhor época de semeadura paras as culturas anuais nos diferentes tipos de solo e ciclos dos cultivares, dentro de niveis de risco de perda pré-estabelecidos. Apesar da metodologia cientifica ser relativamente complexa, os indicativos resultantes e sua aplicação prática é de fácil entendimento e adoção pelos produtores rurais, extensionistas, agentes financeiros, seguradoras e demais usuários".

Ainda, segundo o órgão federal, os dados técnicos necessários para o zoneamento agrícola de risco climático são, principalmente, os dados referentes à fenologia e produtividade, dados de solos, climatológicos e altimétricos. Na Tabela 01 são mostradas as principais características desses quatro principais tipos de zoneamentos existentes, conforme MAPA (op. cit.).

Soc. \& Nat., Uberlândia, 25 (1): 179-190, jan/abr/2013 


\begin{tabular}{|c|c|c|c|c|}
\hline & \multicolumn{4}{|c|}{ Tipo de Zoneamento } \\
\hline & $\begin{array}{l}\text { Aptidão } \\
\text { Agrícola }\end{array}$ & Agroclimático & Agrícola & Agrícola de Risco Climático \\
\hline Análise de risco & $\begin{array}{c}\text {-Potencial do: } \\
\text { *clima } \\
* \text { solo } \\
\text { * fatores socioeco- } \\
\text { nômicos (locais e } \\
\text { regionais) } \\
\text {-Potencial edafo- } \\
\text { climático }\end{array}$ & $\begin{array}{l}\text {-Identifica áre- } \\
\text { as de maiores e } \\
\text { menores riscos } \\
\text { climáticos }\end{array}$ & $\begin{array}{c}\text { - Baseado no tipo } \\
\text { de solo, clima } \\
\text { local, e ciclo } \\
\text { fenológico da } \\
\text { planta. }\end{array}$ & $\begin{array}{l}\text { - Considera o balanço } \\
\text { hídrico, (relação cli- } \\
\text { ma, solo e planta). } \\
\text { - O risco quantifica- } \\
\text { do, através de análi- } \\
\text { ses probabilísticas e } \\
\text { frequênciais. }\end{array}$ \\
\hline $\begin{array}{l}\text { Tipo de indica- } \\
\text { tivo }\end{array}$ & $\begin{array}{c}\text { Área apta } \\
\text { - Área marginal } \\
\text {-Área inapta }\end{array}$ & $\begin{array}{l}\text { - Define melhor } \\
\text { época de plantio } \\
\text { Identifica áreas } \\
\text { com maior poten- } \\
\text { cial de produtivi- } \\
\text { dade }\end{array}$ & $\begin{array}{l}\text {-Define melhor } \\
\text { época de plantio } \\
\text { - Indica cultiva- } \\
\text { res habilitados } \\
\text { para o local }\end{array}$ & $\begin{array}{l}\text { - Por município, tipo } \\
\text { de solo e ciclo da } \\
\text { cultivar. }\end{array}$ \\
\hline $\begin{array}{c}\text { Problemas encon- } \\
\text { trados }\end{array}$ & $\begin{array}{l}\text { - Mapas para as } \\
\text { culturas em grande } \\
\text { escala } \\
\text {-Indicativos apro- } \\
\text { ximados } \\
\text { - Estudos não } \\
\text { consideram ocor- } \\
\text { rência de riscos } \\
\text { toleráveis (secas e } \\
\text { geadas) }\end{array}$ & $\begin{array}{l}\text { - Estudos não } \\
\text { consideram ocor- } \\
\text { rência de riscos } \\
\text { toleráveis (secas e } \\
\text { geadas) } \\
\text {-Potencial climá- } \\
\text { tico para o esta- } \\
\text { belecimento das } \\
\text { culturas agrícolas }\end{array}$ & $\begin{array}{l}\text { - Estudos não } \\
\text { consideram ocor- } \\
\text { rência de riscos } \\
\text { toleráveis }\end{array}$ & $\begin{array}{l}\text { - Estudos não consi- } \\
\text { deram informações } \\
\text { referentes à micro- } \\
\text {-climas } \\
\text { - Interpolação de } \\
\text { dados }\end{array}$ \\
\hline
\end{tabular}

Fonte: MAPA (2010), adaptado.

Org. do autor.

Conforme colocado pelo Ministério da Agricultura, Pecuária e Abastecimento, o Zoneamento Agroclimático, suas metodologias e técnicas utilizadas para sua elaboração, em sua grande maioria, são muito semelhantes, pois, conforme destacam Pereira, Angelocci e Sentelhas (op. cit., p. 436):

Os passos para a elaboração do zoneamento agroclimático de uma grande região envolvem a definição dos objetivos, a escala geográfica do estudo, a caracterização das exigências climáticas das culturas a serem zoneadas, o levantamento climático da região estudada com confecção de cartas climáticas básicas e o preparo das cartas finais de zoneamento.

Nesse sentido, a Tabela 02 traz os quatro passos para o zoneamento das potencialidades climáticas para uma região, conforme apresentado por Sentelhas, Pereira e Angelocci (2000). 
Zoneamento agroclimático: linhas de pesquisa e caracterização teórica-conceitual Cássio Arthur Wollmann, Emerson Galvani

Tabela 02. Etapas para a determinação da potencialidade climática de dada região para elaboração do Zoneamento Agroclimático

\begin{tabular}{|c|c|}
\hline Etapas & Procedimentos necessários \\
\hline \multirow{3}{*}{$\begin{array}{l}\text { Conhecimento da fenologia e carac- } \\
\text { terísticas da cultura }\end{array}$} & $\begin{array}{l}\text { Epoca de crescimento, duração do ciclo da cultura (da semeadura até } \\
\text { a maturação); }\end{array}$ \\
\hline & $\begin{array}{l}\text { Estádios críticos do desenvolvimento - fases fenológicas mais suscep- } \\
\text { tíveis às condições adversas de clima; }\end{array}$ \\
\hline & Duração das fases fenológicas; \\
\hline \multirow{2}{*}{ Necessidades climáticas da cultura } & Limites requeridos pela cultura para cada elemento do clima; \\
\hline & Elementos climáticos a serem considerados; \\
\hline $\begin{array}{l}\text { Mapeamento dos elementos cli- } \\
\text { máticos }\end{array}$ & $\begin{array}{l}\text { Por interpolação com auxílio de sistema de informações geográficas } \\
\text { (SIG). Normalmente utilizado para os elementos do Balanço Hídrico. } \\
\text { Por equação de regressão que relaciona o elemento climático com fato- } \\
\text { res geográficos (latitude, altitude e longitude) da região. Normalmente } \\
\text { utilizada para a temperatura do ar. }\end{array}$ \\
\hline \multirow[b]{3}{*}{$\begin{array}{l}\text { Sobreposição das cartas climáticas } \\
\text { (Zoneamento Agroclimático) }\end{array}$} & Áreas onde a cultura pode ser cultivada economicamente (Área APTA); \\
\hline & $\begin{array}{l}\text { Áreas onde a cultura encontrará sérias restrições climáticas para seu } \\
\text { crescimento e desenvolvimento (Área INAPTA); }\end{array}$ \\
\hline & $\begin{array}{l}\text { Áreas onde as restrições climáticas não são totalmente limitantes ao } \\
\text { cultivo (Área MARGINAL). Áreas Marginais poderão ser utilizadas se: } \\
\text { Os solos forem profundos, no caso de deficiência hídrica; } \\
\text { A irrigação for economicamente viável; } \\
\text { Houver disponibilidade de variedades resistentes; }\end{array}$ \\
\hline
\end{tabular}

Sobreposição do zoneamento agroclimático às cartas de capacidade de uso do solo e aos fatores socioeconômicos gerando o Zoneamento Ecológico para a cultura em questão.

Fonte: SENTELHAS; PEREIRA; ANGELOCCI (2000, p. 158), adaptado.

Org. do autor.

De acordo com a Tabela 02, tanto a terceira quanto a quarta etapa de realização do zoneamento agroclimático preveem a utilização de técnicas de cartografia e geoprocessamento, especialmente as técnicas relacionadas à cartografia de síntese, referindo-se à sobreposição das cartas climáticas (quarta etapa).

Atualmente, com o avanço tecnológico da informática voltada à cartografia, tal sobreposição e criação de cartas síntese para a construção do Zoneamento
Agroclimático é também possível através de softwares de geoprocessamento, conhecidos como Sistemas de Informações Geográficas (SIG), além da utilização de Sistemas de Informações Agrometeorológicas (SIA), que pode ser considerado um conjunto de técnicas que visam auxiliar no planejamento das atividades agrícolas, e está fundamentada em três bases de dados: os dados meteorológicos, os biológicos (necessidades bioclimáticas) e os dados de previsão do tempo. 
Assim, a união de um SIA e um SIG geram informações agrometeorológicas muito ricas, e que atualmente podem ser inseridas em um Zoneamento Agroclimático, a fim de se tornar mais fiel às realida- des climáticas de uma região, trabalhando-se com a sucessão e variabilidade do tempo. A Figura 02 mostra de forma sintética o esquema do funcionamento de um SIA.

Figura 02. Esquema do funcionamento de um SIA.

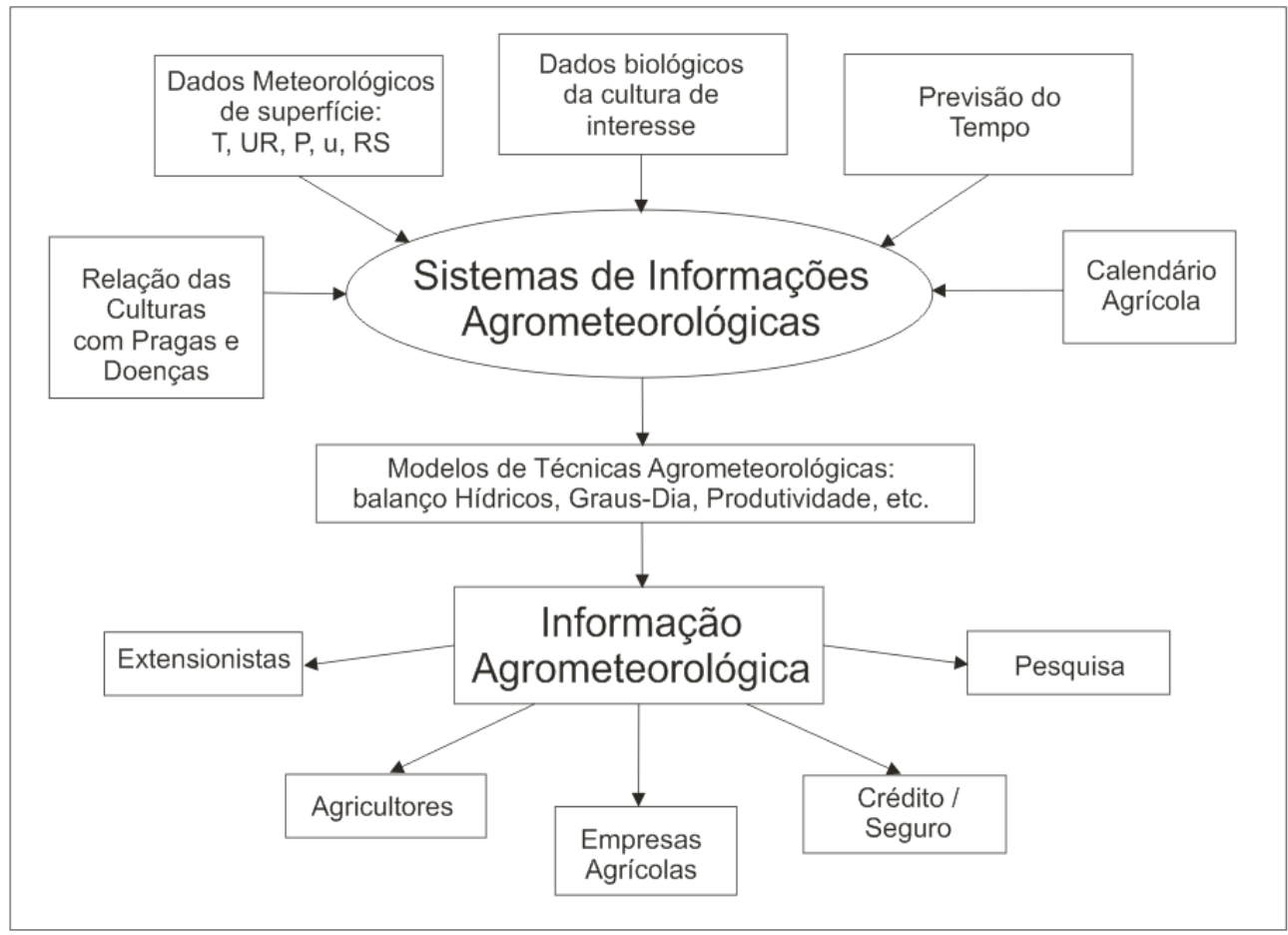

Fonte: SENTELHAS; PEREIRA; ANGELOCCI (2000, p. 160), adaptado.

Org. do autor.

No Brasil, os estudos de zoneamento agroclimático são muito mais recentes, sendo grande parte deles desenvolvidos após a década de 1990, especialmente os realizados pela EMBRAPA, coordenados pelo Pesquisador e Prof. Dr. Eduardo Delgado de Assad.

Em nível estadual, destacam-se o Instituto Agronômico de Campinas (IAC), com diversos estudos agroclimáticos para o Estado de São Paulo; o Instituto Agronômico do Paraná (IAPAR), cujas pesquisas são lideradas pelo Prof. Paulo Henrique Caramori, que tem desenvolvido pesquisas ligadas à influência das geadas em diversos cultivares; a Empresa de Pesquisa Agropecuária e Extensão Rural De Santa Catarina (EPAGRI);

No Brasil, os estudos de zoneamento agroclimático estendem-se sobre diversas culturas co- nhecidas, especialmente as monoculturas realizadas em grandes fazendas (latifúndios) voltadas para a exportação. No entanto, também há vários estudos sobre culturas agrícolas regionais e de abastecimento interno, como zoneamento agroclimático do café, algodão, soja, aveia, milho, entre outros (como pode ser consultado na Revista Brasileira de Agrometeorologia, edições de 2001, 2003, 2005 e 2007).

\section{CONCLUSÕES}

A partir do momento no qual se optou por trabalhar com o tema zoneamento agroclimático, constatou-se que muitas linhas de pesquisa, não só dentro da Geografia, mas na Agronomia, Botânica, Administração e Economia também têm se preocupa- 
do com esta problemática. Pode-se afirmar, portanto, que a Agronomia como linha de pesquisa para o desenvolvimento de trabalhos desta natureza, pode ser considerada a área do conhecimento que possui o maior acervo de pesquisas dedicadas ao zoneamento agrícola quando comparada com os estudos realizados pela Climatologia Geográfica.

Por fim, este estudo sobre a discussão dos conceitos ligados ao Zoneamento Agroclimático bem como de suas aplicabilidades procurou, de forma sucinta, sistematizar os principais estudos teóricos existentes.

\section{REFERÊNCIAS}

BURGOS, J. J. El Clima. In: BURGOS, J. J. Las Ciencias Agrícolas en América Latina: Progresso y Futuro. San José: Trejos Hnos, 1967. Cap. 3. p. 85-109.

EMPRESA DE PESQUISA AGROPECUÁRIA E EXTENSÃO RURAL DE SANTA CATARINA. Zoneamento Agrícola de Espécies Florísticas e Ornamentais. Disponível em: < http://ciram.epagri. rct-sc.br/portal/website/index.jsp?url=jsp/agricultura/ floricultura.jsp\&tipo=agricultura $>$. Acesso em 25 de setembro de 2008.

FEIO, M. Clima e Agricultura. Lisboa: Ministério da Agricultura, Pescas e Alimentação, 2001.

GALVANI, E. Considerações acerca dos estudos bioclimáticos. In: CARLOS, A. F. A.; OLIVEIRA, A. U. Geografias de São Paulo: A Metrópole do Século XXI. 2004. p. 221-229.

GRISOLLET, H.; GILMET, B.; ARLERY, R. Climatologie-Méthodes et Pratiques. Paris: Gauthier-Villars et Cie. 1952. Cap. 24. p. 314-337.

INSTITUTO AGRONÔMICO DE CAMPINAS. Governo do Estado de São Paulo. Secretaria da Agricultura e Abastecimento. Boletim 200 - Instruções agrícolas para as principais culturas econômicas. 2. ed. Campinas: Ed. do IAC, 1998. 393 p.
KIMBALL, M. H.; GILBERT, D. E. Pantclimate Mapping: The key to conservation of resources. In: SYMPOSIUM GROUND LEVEL CLIMATOLOGY. 2. 1970, Berkeley. Annals... Berkeley: University of Berkeley, 1970. p. 67-92.

LEE, D. H. K. Clima e desenvolvimento econômico nos trópicos. Rio de Janeiro: O Cruzeiro S. A., 1968. 166 p. $3 \mathrm{v}$.

MINISTÉRIO DA AGRICULTURA, PECUÁRIA E ABASTECIMENTO. Zoneamento Agrícola de Risco Climático: Instrumento de Gestão de Risco Utilizado pelo Seguro Agrícola do Brasil. Disponível em: www. agricultura.gov.br. Acesso em: 20 de jan. 2010.

MOTA, F. S. Meteorologia agrícola. 7. ed. São Paulo: Nobel, 1983.

MOTA, F. S.; AGENDES, M. O. O. Clima e agricultura no Brasil. Porto Alegre: SAGRA, 1986.

NIMER, E. Climatologia do Brasil. Rio de Janeiro: IBGE/SUPREN, 1979. p. 9-19.

OMETTO, J. C. Bioclimatologia Vegetal. São Paulo: Agronômica Ceres Ltda. 1981. 440 p.

PELUZIO, J. B. E.; SANTOS, A. R.; PELUZIO, T. M. O. et. al. Zoneamento Agroclimático da Alpinia purpurata no Estado do Espírito Santo. In: CONGRESSO BRASILEIRO DE FLORICULTURA E PLANTAS ORNAMENTAIS, 17., 2009, Aracaju. Anais... Aracaju: UFS, 2009. 1 CD-ROM.

PEREIRA, A. R.; ANGELOCCI, L. R.; SENTELHAS, P. C. Agrometeorologia - Fundamentos e aplicações práticas. Porto Alegre: Agropecuária, 2002.

ROBREDO, L. H. Meteorología, Física y Climatología Agrícolas. Barcelona: Salvat Editores S. A., 1952. $370 \mathrm{p}$. 
SENTELHAS, P. C.; PEREIRA, A. R.; ANGELOCCI, L. R. Meteorologia Agrícola. 3. ed. Piracicaba: ESALQ, 2000. 172 p.

SILVA, T. G. F. Zoneamento Agroclimático do Estado da Bahia para a cultura da Atemóia (Annona cherimola Mill. x Annona squamosa L.). Dissertação (Mestrado em Agronomia). Universidade Federal de Viçosa, Viçosa, 2006.

SMITH, L. P. Methods in Agricultural Meteorology. [s./l.]: [s./ed.], 1975.

THORNTHWAITE, C. W.; MATHER, J. R. The water balance. Centerton: Laboratory of Climatology. 1955. 104 p. (Publications in Climatology, v. 8, n. 1.).

TUBELIS, A. A chuva e a produção agrícola. São Paulo: Nobel, 1988. 86 p.

TUBELIS, A.; NASCIMENTO, F. J. L.; FOLONI, L. L. Meteorologia e Climatologia Agrícola. Botucatu: FCMBB, 1972. 487 p. 3 v.

VILLA NOVA, N. A.; SANTIAGO, A. V.; REZENDE, F. C. Energia solar - Aspectos físicos e de captura pela biomassa. Piracicaba: ESALQ, 2001. 20 p. 